\title{
D-22 USGS PETROLEUM ASSESSMENT OF THE WORLD - HOW DO THE RIFT BASINS OF THE MEDITERRANEAN RANK?
}

\begin{abstract}
The USGS recently completed an assessment of the conventionally recoverable undiscovered oil and gas resources of the world. Of the 246 assessment units in the world, 88 were identified as being, at least in part, in extensional tectonic or rift areas. An additional: 21 assessment units were identified as being in solely extensional areas.
\end{abstract}

In the world, 128 provinces had units assessed. In the Circum-Mediterranean area, four provinces contained 11 assessment units were identified as being in extensional or rift areas. These provinces are the Sirte Basin, Yemen, Red Sea Basin, and the Provence Basin; together they have a total petroleum endowment of 104.9 billion barrels of oil equivalent (BBOE). Total petroleum endowment is defined here as the sum of cumulative production, remaining reserves, and mean undiscovered resources as estimated by the USGS. The individual petroleum endowments (in BBOE) for these provinces and their relative world rankings (in parentheses) are:

Sirte Basin

Red Sea Basin (includes the Gulf of Suez Basin)

Yemen

Provence Basin

\section{5 (18th)}

30.3 (29th)

9.9 (56th)

11.2 (53rd)

In terms of mean undiscovered resource potential for conventional oil (in billion barrels) and relative world rankings, the provinces are:

Sirte Basin

Red Sea Basin

Yemen

Provence Basin

4 (100th) 
For mean estimates of undiscovered conventional natural gas (in trillion cubic feet), the rankings are:

Sirte Basin

Red Sea Basin

Yemen

Provence Basin
$15(57 \mathrm{th})$

60 (20th)

17 (54th)

$51.2(26 \mathrm{th})$

Based on these estimates, the rift basins of the Circum-Mediterranean will remain a major source of petroleum well into this century. Estimates in the offshore Sirte Basin and the entire Provence Basin of the western Mediterranean Sea carry geologic risk in the reported estimates. Additional rift basins that were not appraised are known in the Circum-Mediterranean and their inclusion would increase the petroleum resource potential of the rift basins in this region. 